\title{
Automatic Domestic Stove Using Olive Cake Fuel
}

\author{
Jamil Al Asfar ${ }^{a, *}$, Laith Mazahreh ${ }^{b}$ \\ ${ }^{a}$ Jamil Al Asfar, The University of Jordan, Amman, Jordan \\ ${ }^{b}$ Laith Mazahreh, Ministry of Energy and Mineral Resources, Amman, Jordan
}

\begin{abstract}
Desertification is considered one of the main problems that concerns mankind. Wood stoves and fireplaces mainly use wood as the main source of energy, which would lead to desertification and global warming. This paper presents the design of a domestic automatic stove that primary uses olive cake as the major source of energy. Moreover, a prototype of the theoretical model was built, and experimentally tested for 65 minutes. The efficiency of the prototyped model reached a value of $56.25 \%$. .
\end{abstract}

Keywords: Olive Cake, Heating System, Biomass, Biofuels, Automatic.

\section{Introduction}

Energy resources in general, can be mainly divided into renewable energy resources and non-renewable energy resources. Non-renewable energy resources, also called finite resources, such as: fossil fuels, earth minerals...etc. would not last for a long time, forcing us to rely mainly on renewable energy resources such as, solar energy, biomass energy, wind energy...etc. Another problem arises from non-renewable resources is its greenhouse gases emissions compared to the renewable resources. Gavaskar et al. (2002), made an economic study on biomass resources, and they have concluded the reduction of both greenhouse emissions and air pollution when replacing fossil fuels with biomass resources [1]. Biomass energy is the energy that is originated from organic matter; it is considered renewable resource of energy because of its repeating life cycle. Olive cake, which is the waste of oil mills, is one of the great resources that is available in Mediterranean countries at large amounts and at low cost. Jordan, one of the popular countries regarding olive trees, has almost 1300 millions square meters covered with olive trees [2]. These trees produce 180,000 tons of olives each year [2]. Thirty five percent of the total olive mass-produces solid waste, also called "olive cake" which is almost 63,000 tons annually.
Besides olive cake, Jordan is also rich when considering oil shale. Oil shale in Jordan represents a significant resource, with an available amount of 70 billion tons of oil shale that contains more than 7 billion tons of oil [3]. However, the heating value of the oil shale is much less that the heating value of the olive cake.

Al-Asfar et al. (2016), have experimentally measured properties of olive cake, oil shale and other biomass fuels, the conclusion of their experimental work revealed the lower and higher heating values of olive cake and oil shale, which can be approximated to an average value of $20000,7550[\mathrm{~kJ} / \mathrm{kg}$ ] respectively [4]. Besides its great heating value, olive cake is considered to be an environmentally friendly fuel with a very low Sulphur content, $<0.1$ wt. $\%$.

These properties encouraged the share of biomass in total power generation. However, the generation of power from biomass fuels was at large scale (industrial scale), and rarely being used in small-scale applications (domestic fireplace).

In this work, an automatically controlled domestic stove will be designed, and will be simulated using ANSYS software. In addition, a prototype with the needed controls and sensors will be built and experimentally tested in order to find the experimental value of the efficiency.

${ }^{*}$ Corresponding author. Tel.: +962795568716

E-mail: jasfar@ju.edu.jo

(C) 2018 International Association for Sharing Knowledge and Sustainability

DOI: $10.5383 /$ ijtee. 17.01 .008 


\section{Theoretical and Experimental Procedure}

Initially, the theoretical stove model was sized according to the default size of a domestic fireplace. Then, all the heat transfer constants and properties were calculated in order to find the boundary conditions needed to simulate the results inside ANSYS. Finally, the theoretical model was simulated using ANSYS software and the temperature distributions of the stove were conducted.

The preparation of the olive cake was the initial step in the experimental work. Olive cake was initially pulverized using a hammer until obtaining a sand like size of the olive cake sample. Then, the control circuit was assembled with all the required sensors and actuators and was tested before installing it the system. The metal stove was machined to meet the feeder system requirements and the control system was attached to the stove. Finally, the assembled system was tested for 65 minutes and temperatures of the stove surface were collected in order to calculate the efficiency of the prototyped version.

\section{Results and Discussion}

\subsection{Heat Transfer Analyses}

In order to run ANSYS simulation, boundary conditions such as: the inside and outside coefficient of heat transfer, inside and outside temperatures were required. In this section, a brief calculation of these conditions will be discussed.

For a standard room with a temperature of $23{ }^{\circ} \mathrm{C}$, a standard value of heat transfer coefficient was used. (Room without fans or blowers), ho $=5\left[\mathrm{~W} / \mathrm{m}^{2} . \mathrm{K}\right][5]$.

The inside heat transfer coefficient was calculated using equation (1) below [6]:

$$
\begin{aligned}
& \mathrm{h}_{\mathrm{i}}=21.824\left[\mathrm{~W} / \mathrm{m}^{2} \cdot \mathrm{K}\right] . \\
& \mathrm{Nu}=0.023 \times \operatorname{Re}^{\frac{4}{5}} \times \operatorname{Pr}^{0.3}=\frac{\mathrm{h}_{\mathrm{i}} \times \mathrm{D}}{\mathrm{k}}
\end{aligned}
$$

Moreover, the inside and outside temperatures were set to be $192,23{ }^{\circ} \mathrm{C}$, respectively. Other properties relating to olive cake, such as olive cake's composition and heating values were used from Al-Asfar et al. (2017) study [7]. These properties are summarized in table 1 shown below.

Table 1. Ultimate (dry, ash free basis) and proximate olive cake

\begin{tabular}{|c|c|c|c|}
\hline \multirow{6}{*}{ Ultimate } & Chemical element & $w t \%$ & $\mathrm{DAF}(\mathrm{mol} \%)$ \\
\hline & $\mathrm{C}$ & 53.9 & 0.3432 \\
\hline & $\mathrm{H}$ & 6.1 & 0.4660 \\
\hline & $\mathrm{O}$ & 338.5 & 0.1832 \\
\hline & $\mathrm{N}$ & 1.4 & 0.0074 \\
\hline & $\mathrm{S}$ & 0.1 & 0.0002 \\
\hline \multirow{8}{*}{ Proximate } & Volatile matter & 71.5 & 80.7 \\
\hline & Fixed Carbon & 17.1 & 19.3 \\
\hline & Moisture & 6.9 & - \\
\hline & Ash & 4.5 & - \\
\hline & Density $\left[\mathrm{kg} / \mathrm{m}^{3}\right]$ & \multicolumn{2}{|r|}{600} \\
\hline & Lower Heating Value [kJ/kg] & \multicolumn{2}{|r|}{19,500} \\
\hline & Higher Heating Value $[\mathrm{kJ} / \mathrm{kg}]$ & \multicolumn{2}{|r|}{21,200} \\
\hline & Stoichiometric air fuel ratio & \multicolumn{2}{|r|}{6.5} \\
\hline
\end{tabular}
analyses [7].

\subsection{Control Circuit}

When the main idea of this study is to make an automatically controlled olive cake feeder, therefore, a motor with a worm feeder is needed for feeding the pulverized olive cake. In addition, a thermocouple is also needed to interrupt or to activate the feeding process.

In order to close the circuit, an on-off controller is needed for sending these signals between the thermocouple's reading and the motor. Figure 1 shows components used to drive the system.

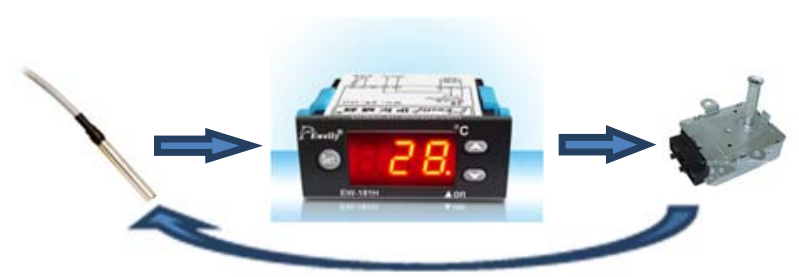

Fig. 1. Control circuit workflow

Olive cake feeding will continue until the thermocouple's reading reaches the upper specified set point temperature of the stove's surface, and will start running again when the reading reaches the lower set point temperature.

\subsection{Fuel Preparation}

Olive cake was bought from an olive mill located in AjlounJordan. Because of its cylindrical, which is not practical for our experiment, olive cake was pulverized using a hammer in order to make it in a sand like shape. Figure 2 shows the pulverization process of the olive cake sample.
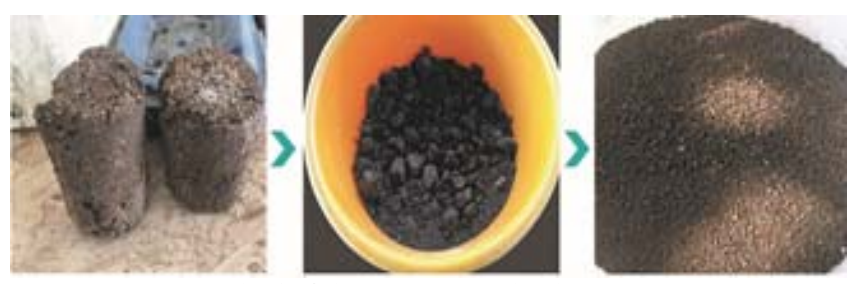

Fig. 2. Olive cake pulverization

\subsection{ANSYS Simulation}

As stated above, the calculated and assumed heat transfer properties were used as boundary conditions in order to run the simulation. Figure 3 shows the temperature distribution of the theoretical designed stove. It is observed from Figure 3 that surface temperature of the stove casing could reach a value of $120^{\circ} \mathrm{C}$. Therefore, the controlled temperature can be set to this value if high heating load is required.

\subsection{Prototype}

A modification of an ordinary wood stove was achieved using the previously discussed control components. Figure 4 and 5 illustrates the main components of the prototyped model which consists mainly of:

- Buner's Case: this is the major component where other components are attached to it. The burner's case will transfer heat from inside to outside via radiation and convection.

- Burner's Door: encloses the system. Drilled holes on this component will help in atomizing olive cake with fresh air. 
- Fuel Tank: this component will store pulverized olive cake that will be fed to the inside of the stove.

- Worm shaft: transfers olive cake fuel from fuel tank to the stove.

- Motor: this component will force the worm shaft to rotate.

- On-off controller: This brain component will give the signal to the motor or interrupt the signal depending on the thermocouple's reading.

- Thermocouple: sensor used to sense temperature

- Chimney: burned gases will flow through this component.

- Fuel Feeder: worm shaft, motor and fuel tank are attached to the fuel feeder.

- Electrical Plug: transfers electricity to the controller and the motor

- Aluminum Sheet Slide: pulverized olive cake will settle down on the center of the burner with the help of this slide.

- Door Lock: prevents the door from opening by mistake.

Data from thermocouple's reading were continuously collected up to 65 minutes. After collecting the data, the graph (Figure 6) was plotted. This graph shows the performance of the built prototype. The irregular curve represents the temperature of the casing, and the constant curve shows the operation period of the motor. This prototype was tested at an ambient temperature of $25^{\circ} \mathrm{C}$, and the data from the thermocouple's reading were collected in order to calculate the efficiency of the stove. The efficiency was calculated as the ratio of the output heat available around the casing of the stove to the input fuel and electricity consumption used during the data collection period.

From Figure 6, it can be observed that the first reading was $25^{\circ} \mathrm{C}$, which is the ambient temperature as stated earlier. Temperatures reading were flowing around $50{ }^{\circ} \mathrm{C}$ which is the set point temperature were the controller will stop the motor from operating.

Temperature peaks above $50{ }^{\circ} \mathrm{C}$ and below $47{ }^{\circ} \mathrm{C}$ are due to unsteady fuel feeding that results from fuel being stuck on the aluminum slide that results in sudden high flow rate of fuel and sudden low flow rate of fuel. The low fuel flow rate will result in temperature drop and high temperature peaks result from high olive cake flow rates. Motor operation range was between $47^{\circ} \mathrm{C}$ and $50^{\circ} \mathrm{C}$, this temperature difference was set by the onoff controller.

The efficiency was calculated from the graph using a simple relation, which is the output desired over the paid input energy

$$
\begin{aligned}
& \text { Output }=\text { Convection }+ \text { Radiation heat transfer energy, } \\
& \begin{aligned}
\text { Input }= & \text { Electrical energy consumption }+ \\
& \text { Fuel energy consumption }
\end{aligned} \\
& \boldsymbol{\eta}=\frac{\text { Output }}{\text { Input }}
\end{aligned}
$$

The motor was operating for 13.3 minutes that consumed almost 100 grams of pulverized olive cake. The depth, width and height in $\mathrm{cm}$ of the burner were 60,40 and 30 respectively. Other properties such as motor power, and emissivity were set to $4 \mathrm{~W}$ and 0.9 (black painted steel) respectively. Using the previous simple relation, the calculated efficiency reached

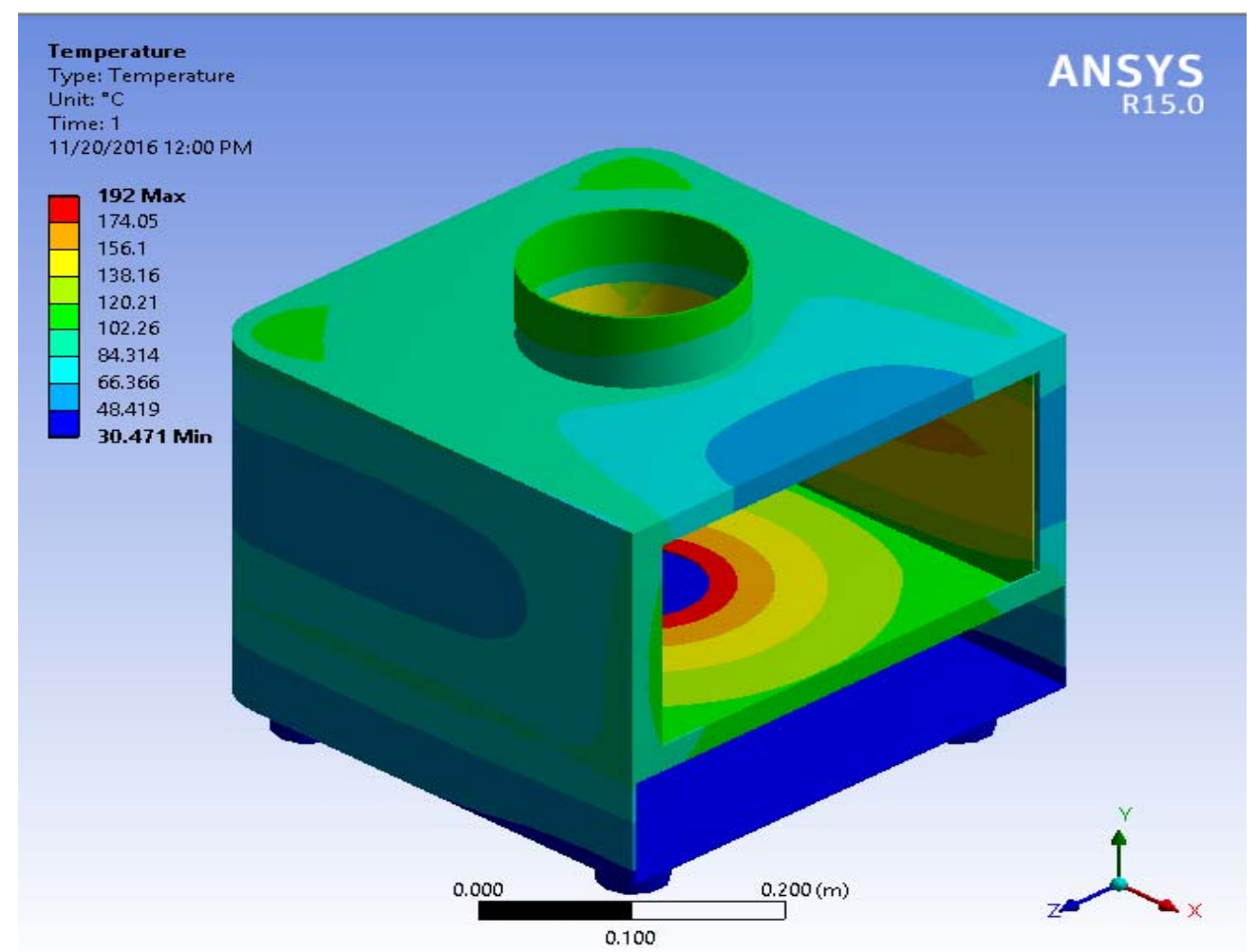

Fig. 3. Theoretical stove temperature distribution 

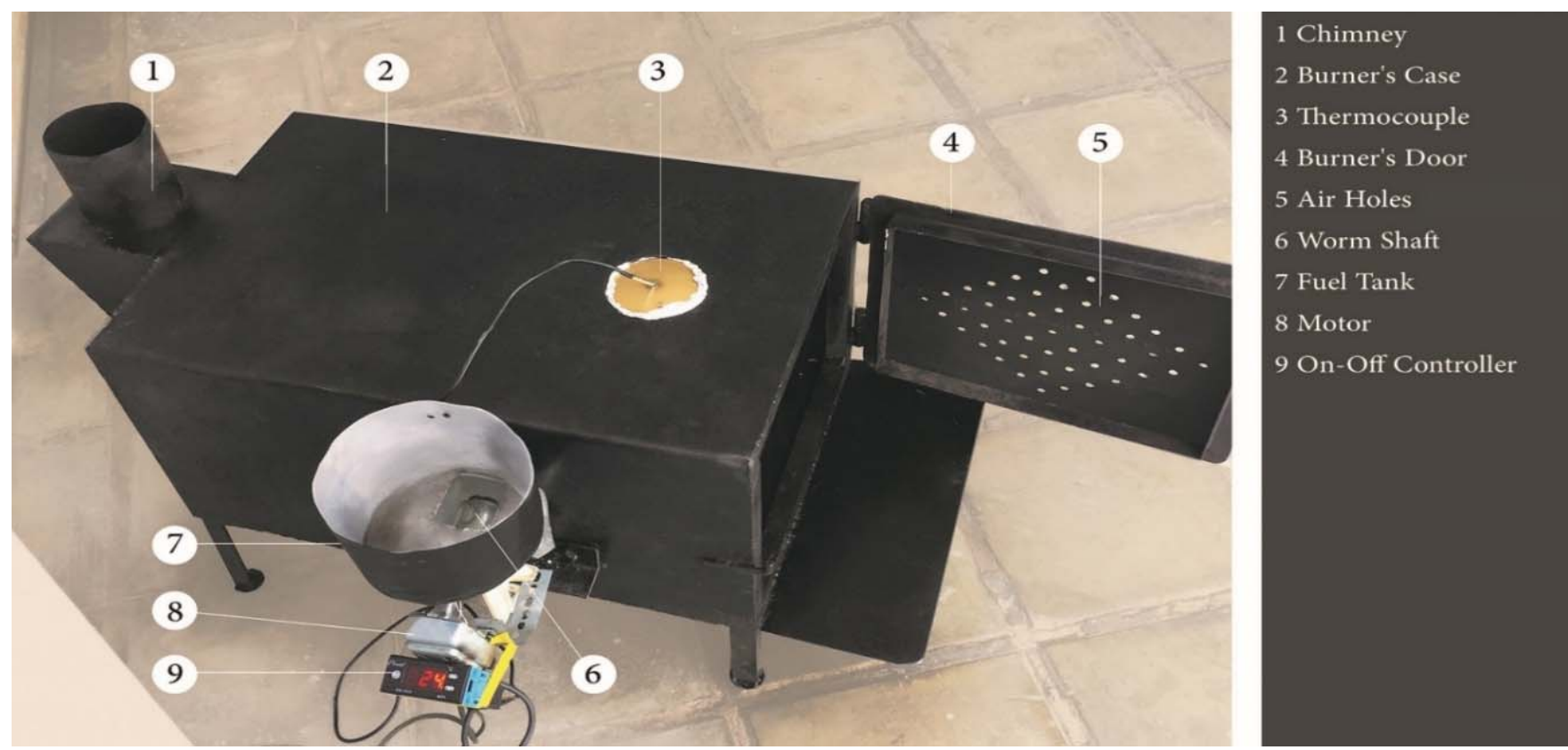

Fig. 4. Prototype components part 1
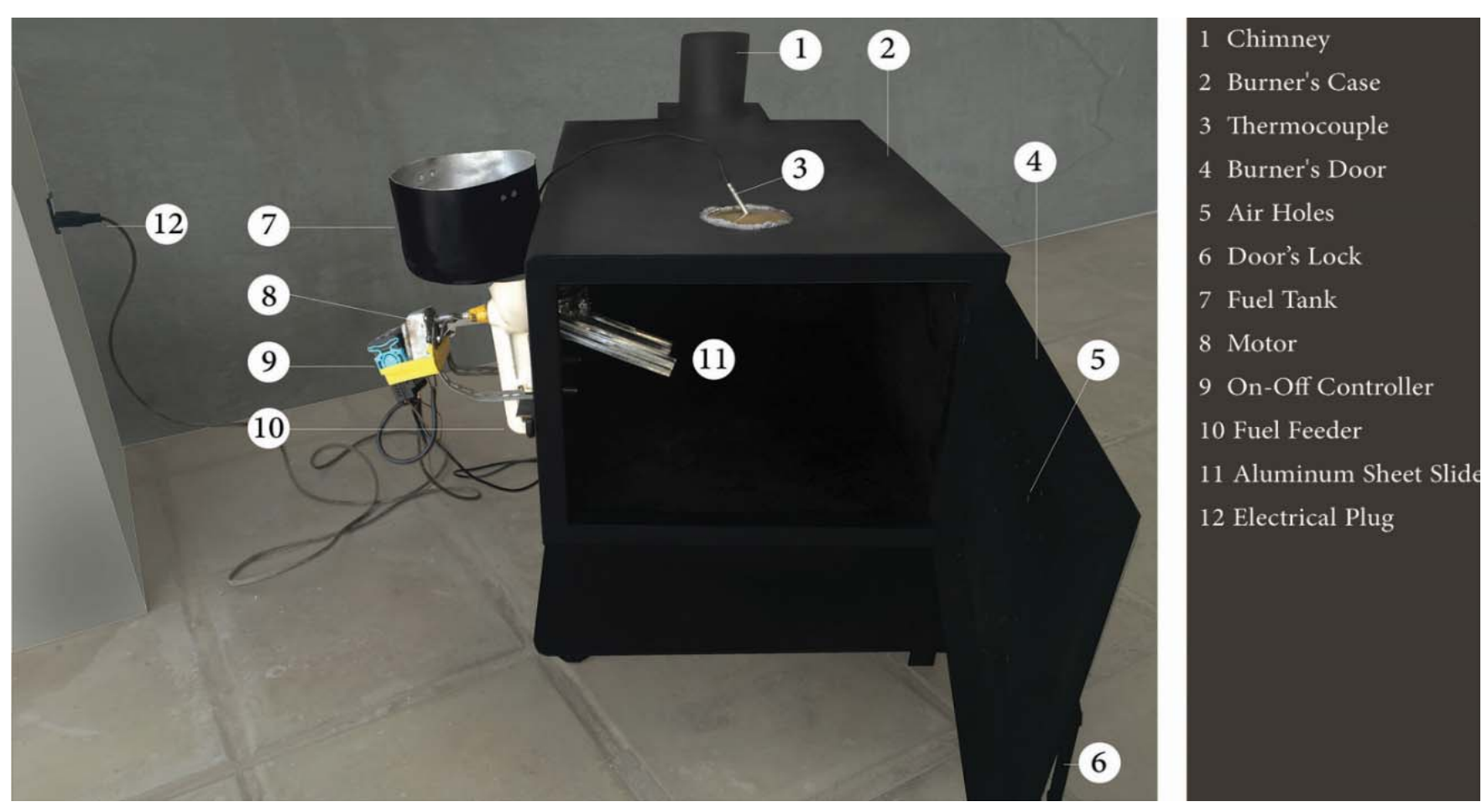

Fig. 5. Prototype components Part 2 


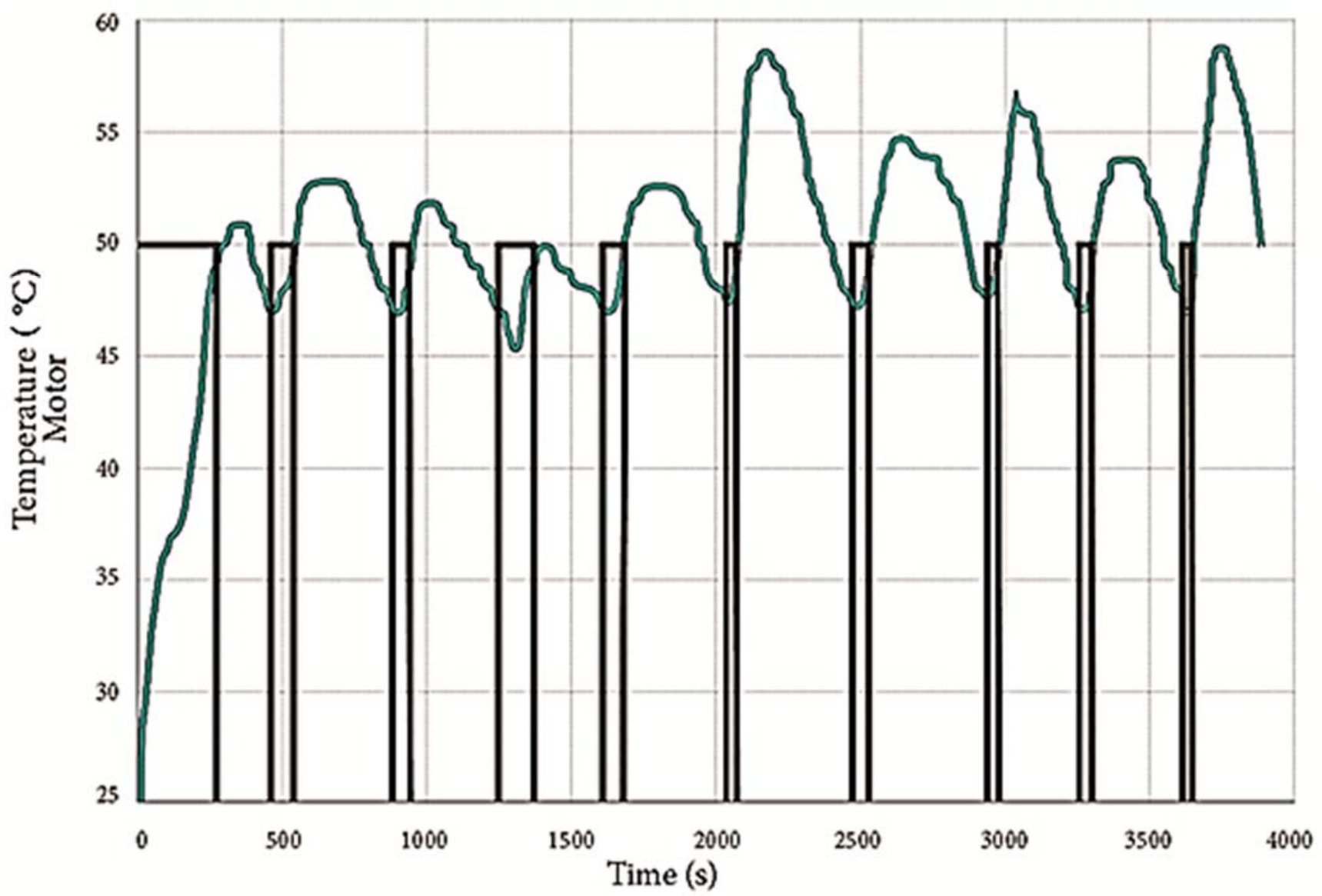

Fig. 6. Prototype performance curve

\section{Conclusion}

A series of theoretical and experimental work were conducted to test the behavior of a domestic stove that uses pulverized olive cake as a source of energy. The theoretical model was simulated using ANSYS software, were temperature distributions of the model were conducted. The built model showed great performance considering both the efficiency and continuous operation.

The efficiency obtained from the experimental work reached a value of $56.25 \%$. Control circuit with all the required components worked smoothly continuous.

Using olive cake as a source of energy would not only reduce desertification that is considered one of the major problems facing most of Mediterranean countries, but also reduces both greenhouse emissions and air pollution.

It may be concluded that solid waste biomass such as olive cake represents an alternative fuel that that possibly would replace partially fossil fuels in near future, with the presence of automatic stoves that would burn olive cake without the need of any external human power.

\section{Nomenclature}

h $\quad$ Heat transfer coefficient, $W / \mathrm{m}^{2} . \mathrm{K}$

$\mathrm{k} \quad$ Thermal conductivity, W/m.K

D Diameter of burning circle, $\mathrm{m}$

Greek Symbols

$\eta \quad$ Efficiency

Subscripts

i Inside

o Outside

Non-dimensional Numbers

Re Reynolds number

$\mathrm{Nu} \quad$ Nusselt Number

Pr Prandtl Number 


\section{References}

[1] Gavaskar J., Pillai V., Sanker N., Ayyapan M., Saravanan M., and Pasupathy A., (2012), Energy economics study on biomass energy conversion techniques. IJRMET 2 (1):4953.

[2] Ministry of Agriculture (2016), Annual Report, Amman, Jordan.

[3] Ministry of Energy and Mineral Resources (2016), Annual Report, Amman, Jordan.
[4] Al Asfar J., Hammad A., Sakhrieh A., and Hamdan M., 2016. Two-dimensional numerical modeling of combustion of Jordanian oil shale. Energy sources, Part A: Recovery. Utilization and Environmental Effects 38 (9):1189-96.

[5] M. Alsaad and M. Hammad, Heating and Air Conditioning, 5th edition 1995, Jordan: AJIAL Press.

[6] Incorpera, DeWitt, Bergman and Lavine, Heat and Mass Transfer, 6th edition 2005, WILEY, USA.

[7] Al Asfar J., AlShwawra A., Sakhrieh A., and Hamdan M., (2017). Combustion characteristics of solid waste biomass, oil shale and coal. Energy sources, Part A: Recovery. Utilization and Environmental Effects 40 (3):335-342. 